\title{
GC-MS Analysis of Indrakeeladri Native Medicine used in the Treatment of Stroke
}

\author{
Sundarachary Nagarjunakonda' ${ }^{1}$ Sridhar Amalakanti ${ }^{2}$, Sristi Ram Dhishana ${ }^{3}$, Maddi Ramaiah ${ }^{4}$, Lalitha Rajanala ${ }^{5}$
}

Sundarachary Nagarjunakonda $^{1}$, Sridhar Amalakanti ${ }^{2}$, Sristi Ram Dhishana ${ }^{3}$, Maddi Ramaiah $^{4}$, Lalitha Rajanala ${ }^{5}$

'Department of Neurology, Guntur Medical College, Guntur, INDIA.

2Department of Neurology, Guntur Medical College, Guntur, INDIA.

Intern, Guntur Medical College, Guntur.

${ }^{4}$ Department of Pharmacognosy, Hindu Col-

lege of Pharmacy, Guntur, INDIA.

${ }^{5}$ Department of Neurology, Guntur Medical

College, Guntur, INDIA

\section{Correspondence}

Dr A Sridhar, Resident in Neurology, Dept of Neurology, Govt General Hospital, Guntur 522002, INDIA

Telephone: +91-8985183641

E-mail: iamimenotu@gmail.com

History

- Submission Date: 08-07-2016;

- Review completed: 20-07-2016;

- Accepted Date: 05-08-2016.

DOI : 10.5530/pj.2017.1.17

Article Available online

http://www.phcogj.com/v9/i1

Copyright

(C) 2016 Phcog.Net. This is an openaccess article distributed under the terms of the Creative Commons Attribution 4.0 International license.

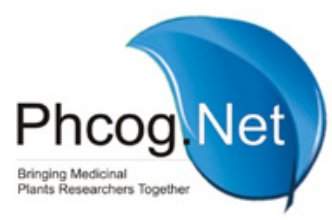

\begin{abstract}
Context: A stroke or cerebrovascular disease is an abrupt onset of neurological deficit that is attributable to a focal vascular cause. Antiplatelet drugs, anticoagulants and thrombolytics are used in ischemic stroke. Indrakeeladri, is a village in Andhra Pradesh in India where traditional local practitioners prescription has long been practiced for treatment of stroke by using unknown and undisclosed formulation (gulikalu) without any name and labeling. Patients who have taken treatment at Indrakeeladri have noticed improvement in their symptoms particularly in speech. Aims: We endeavoured to analyze the formulation to know its composition as this analysis might help us in preparation of newer drugs for stroke. Settings and Design: GC MS analysis. Methods and Material: The sample was powdered and tested for its solubility in different solvents of increased polarity strength and then subjected to Gas Chromatography Mass Spectrometry (GCMS) analysis in order to know its chemical components. Results: The sample was soluble only in water. The GC-MS analysis of the test sample revealed the presence of methyl tetradecanoate, dodecanoic acid methyl ester and methyl 10-methyl undecanoate as the major constituents. These substances are known to have inhibitory effect on blood coagulation. Conclusions: Further studies need to be carried out to find out whether these components of native medicine have a role in the treatment of stroke or not.
\end{abstract}

Key words: Native medicine, Stroke, Methyl tetradecanoate, Dodecanoic acid methyl ester, Methyl 10-methyl undecanoate

Key Messages: The GC-MS analysis of the Indrakeeladri native medicine used in the treatment of stroke revealed the presence of methyl tetradecanoate, dodecanoic acid methyl ester and methyl 10-methyl undecanoate as the major constituents.

\section{INTRODUCTION}

Stroke is a term used to describe an abrupt onset of focal neurologic deficit due to vascular damage in the brain that lasts at least 24 hours. ${ }^{1,2}$ Stroke is one of the major cause of disability and the second leading cause of death worldwide; in 2011 itself it caused 6.2 million deaths. ${ }^{3}$ Stroke can be either ischemic or hemorrhagic in origin. Eighty percent of strokes are caused due to ischemia to the brain caused by occlusion of the cerebral blood vessels. ${ }^{4}$

Antiplatelet drugs, ${ }^{5}$ anticoagulants ${ }^{6}$ and thrombolytics are used in the treatment of ischemic stroke. Antiplatelet drugs like Aspirin and Clopidogrel are used as first line agents for secondary stroke prevention. Recombinant plasminogen activator (rt-PA) is the only biologically effective drug approved by FDA for the treatment of ischemic stroke. ${ }^{6}$ In spite of many recent advances that are available the rate and degree of recovery is yet unsatisfactory in many cases. ${ }^{7}$ Many patients with stroke in India initially approach quack medical practitioners for treatment. A survey conducted in Ludhiana, a city in the North West of India showed that about $48 \%$ of chronic stroke patients received alternative treatment. ${ }^{8}$ Herbal medicine,
Ayurvedic massage, Unani, Siddha, Marma therapy, Reiki therapy, Yoga, Herbal baths, prayer, reflexology and energy transfers are only some method of treatments offered across the country! ${ }^{9}$

The prognosis of stroke is dependent on many variables from age of the patient to the size of the affected area of the brain. ${ }^{10}$ Some patients recover within minutes to hours while some have a lifelong handicap. ${ }^{11}$ Hence unscrupulous practitioners find it easy to administer drugs of unknown value to the gullible public $^{12}$ and if by chance, a mild stroke gets recovered by itself, the success is attributed to the obscure formulation.

In Andhra Pradesh, a progressive state situated in the heart of South India, many people seek treatment from a village called Indrakeeladri. It is located in Krishna district, Andhra Pradesh, India's at $16^{\circ} 30^{\prime} 54.6^{\prime \prime}$ North and 80 $37^{\prime} 22.1^{\prime \prime}$ East. The practice of taking this local formulation for stroke has been in vogue for many decades. Some of our patients who have taken treatment at Indrakeeladri for their previous attacks report that they have noticed improvement in their symptoms particularly in speech. The medicine is given in the form of pellets (gulikalu) and 
is advised to be taken twice daily after the meals. During the treatment period there were strict dietary restrictions. Specifically, brinjal, lady'sfinger, hemp, roots, tubers, green gram, red gram and egg were not to be taken. Each patient incurred about Rs 1000 per month for this treatment. Most of the patient's approached our tertiary care center, Govt. General Hospital (GGH), Guntur, Andhra Pradesh, India for various reasons. Some,

i. Could not afford the cost of treatment.

ii. Did not get recovery from the attack.

iii. Could not follow the dietary restrictions or

iv. Accessed our centre for acute care only- they had intended to approach Indrakeeladri village subsequently.

The patients were neither informed about the composition of the medicine, their source or preparation or the mechanism of action. Was the composition of this native medicine similar to currently used drugs? Do any components of this medicine help in stroke recovery? The drugs prescribed by them have never been studied scientifically. Hence we decided to analyze the drugs to know their composition as this might help us in preparation of a new drug for stroke.

\section{MATERIALS \&METHODS}

\section{Sample collection}

The drug sample (gulikalu) was collected from patients who visited GGH who were treated previously at Indrakeeladri for stroke.

\section{Solubility}

The sample was powdered and tested for its solubility in different solvents of increased polarity index like hexane, benzene, chloroform, ethyl acetate, ethanol, methanol and water. ${ }^{13,14,15}$

\section{GC-MS analysis}

The Gas Chromatography Mass Spectrometry (GC-MS) analysis was done in order to know the components of the sample as it was readily available. The components were analyzed by GC-MS (SHIMADZU QP 2010) employing the electron impact (EI) mode at an ionizing potential of $70 \mathrm{eV}$ with a $30 \mathrm{~m} \times 0.32 \mathrm{~mm}$ film thickness and $1.8 \mu \mathrm{m}$ capillary column (Resteck-624 MS) packed with 5\% phenyl dimethyl silicone at an ion source temperature of $200^{\circ} \mathrm{C}$. For further analysis, GC/MS settings were as follows: the initial column temperature was set at $45^{\circ} \mathrm{C}$ and held for $4 \mathrm{~min}$; the temperature was raised to $50^{\circ} \mathrm{C}$ and then increased up to $175^{\circ} \mathrm{C}$ at a rate of $10^{\circ} \mathrm{C} / \mathrm{min}$ for 2 minutes, and then finally programmed to $240^{\circ} \mathrm{C}$ at a rate of $25^{\circ} \mathrm{C} / \mathrm{min}$, and kept isothermal for 2 minutes. Helium was used as carrier gas with a flow rate of $1.491 \mathrm{ml} / \mathrm{min}$ with a split ratio of 1:10. During sample analysis the column oven temperature was maintained at $280^{\circ} \mathrm{C} . .^{16-20}$

\section{RESULTS}

\section{Solubility}

When the sample was powdered and checked for its solubility in different solvents of increased polarity strength, it was soluble only in water and very poorly in methanol.

\section{Identification of Compounds}

Interpretation of GC-MS spectrum was done using the database of National Institute Standard and Technology (NIST) which consists of more than 62,000 patterns. The spectrum of the unknown component was compared with the spectrum of the known component inherent in the NIST library. The name, molecular weight and structure of the components of the test materials were ascertained. The GC-MS analysis revealed the presence of many compounds. (Figures 1-7, table 1) and the major component was methyl tetradecanoate (76.12\%).

\section{DISCUSSION}

Ischemic strokes are caused either by local thrombus formation or by embolic phenomenon, resulting in occlusion of a cerebral artery. Atherosclerosis, particularly of the cerebral vasculature, is an important cause, although $30 \%$ are cryptogenic. Emboli can arise either from intra- or extra cranial arteries. These cause $20 \%$ of all ischemic strokes. ${ }^{1,2}$ The major signs and symptoms of stroke are a sudden onset weakness on one side of the body, inability to speak, loss of vision or vertigo. ${ }^{32}$ Standard of care for ischemic stroke involves infusion of a thrombolytic agent that dissolves the clot formed in the cerebral blood vessel. Antiplatelet agents such as aspirin and clopidogrel are used to decrease the clot forming propensity of the patient's blood which is the cause of the stroke attack in the first place. Hence they prevent further ischemic strokes and help in reperfusion of the affected brain tissue. ${ }^{33}$

Stroke patients of Andhra Pradesh have been using this native medicine since many decades with the belief that it would cure the disease. It is a matter of interest to know the reason why even educated and sophisticated people and sometimes even professional doctors have also preferred using this medicine. Physically or chemically these compounds do not resemble the drugs used therapeutically in allopathic medicine for treatment of stroke, such as thrombolytic agents and antiplatelet drugs.

The GC-MS analysis of the Indrakeeladri drug sample for stroke revealed the presence of methyl tetradecanoate (76.12\%), dodecanoic acid methyl ester (17.14\%) and methyl 10-methyl undecanoate as the major constituents. Some of these compounds have antiplatelet activity and affect blood coagulation pathways by various mechanisms. Methyl tetradecanoate is one of the components of Aggreceride A which is a platelet aggregation inhibitor from Streptomyces, but its mechanism of action is not yet known. ${ }^{34}$ Tetradecanoic acid methyl ester sodium salt (C14-MES) decreases fibrinogen levels and prolongs prothrombin time and also decreases serum triglyceride levels. ${ }^{35}$ These characteristics hint at a potential role of the formulation for the treatment of ischemic stroke.

Many of these compounds have other medicinal properties. Esters and amides of myristic acid have antibacterial activity. ${ }^{36}$ Methyl tridecanoate is one of the main active components of Acacia pennata which is useful in the prevention of Alzheimer's disease. This is due to the inhibition of $\beta$-amyloid aggregation. ${ }^{37}$ Methyl 12-methyl tridecanoic acid inhibits acetyl cholinesterase and is used as a pesticide. ${ }^{38}$ Lauric acid has very strong bactericidal activity against $P$. acnes and is used in the treatment of acne ${ }^{39}$ Oils rich in lauric acid decrease the ratio of total to HDL cholesterol. ${ }^{40}$

2,8,9-Trioxa-5-aza-1-silabicyclo (3.3.3) undecane is one of the compounds detected in the formulation. It belongs to a group of compounds called silatranes. Silatranes have been used to heal wounds and stimulate hairgrowth. They also possess pharmacological properties like anti-inflammatory, anticancer, antibacterial and fungicidal activities. ${ }^{41}$ Presence of these compounds in the sample may solely or collectively have beneficial effect on stroke. Some of the derivatives of these components are distributed in marine sources, plant sources, animal sources and further investigation is necessary for proper documentation. ${ }^{42}$

Further studies need to be carried out to find out whether these components of native medicine have a definitive role in the treatment of stroke or not. If it is proved that these components can be used in the treatment of stroke, it can lead to discovery of newer drugs which improve the outcome of the stroke patients. 


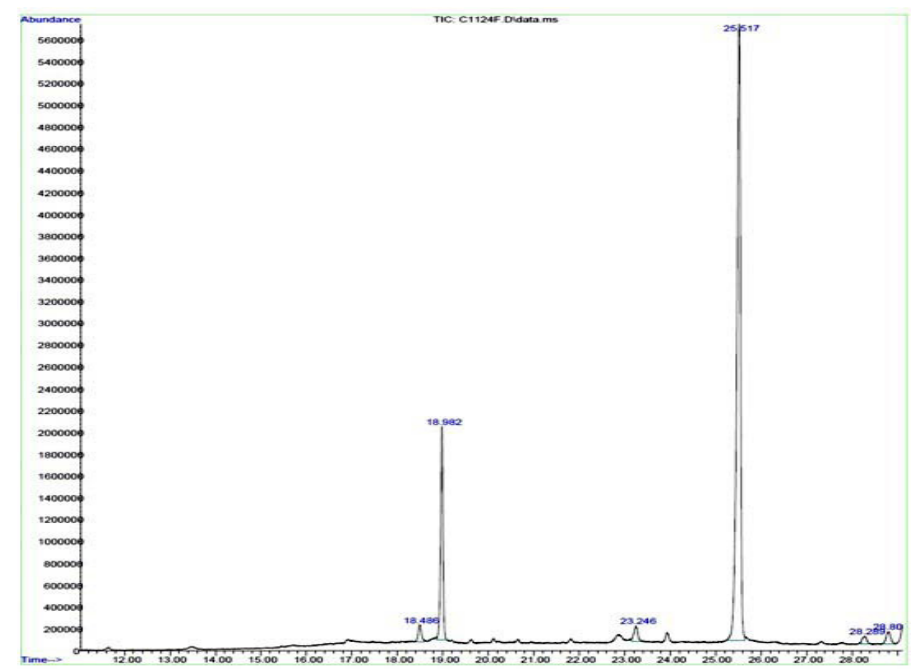

Figure 1

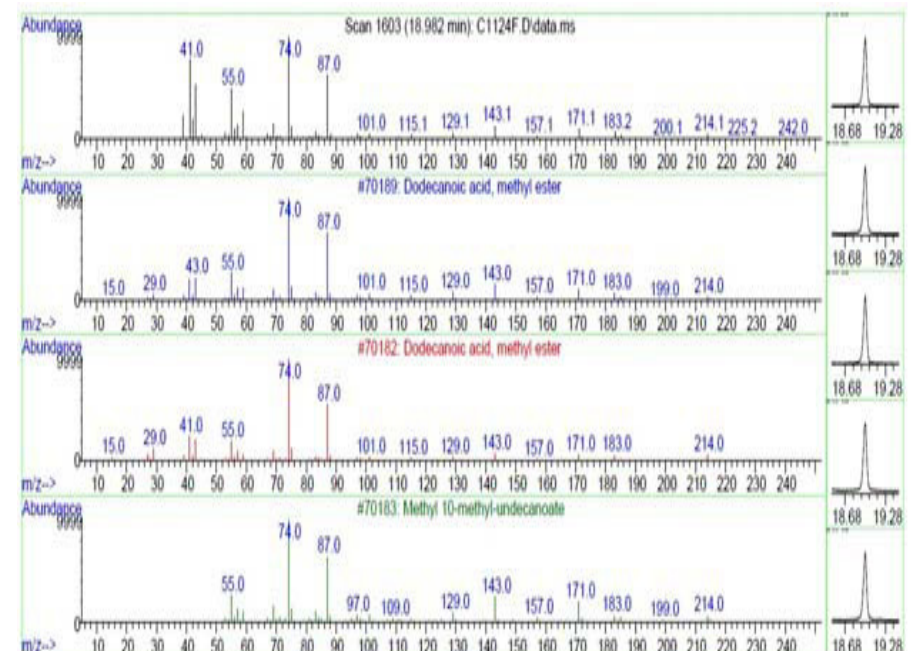

Figure 3

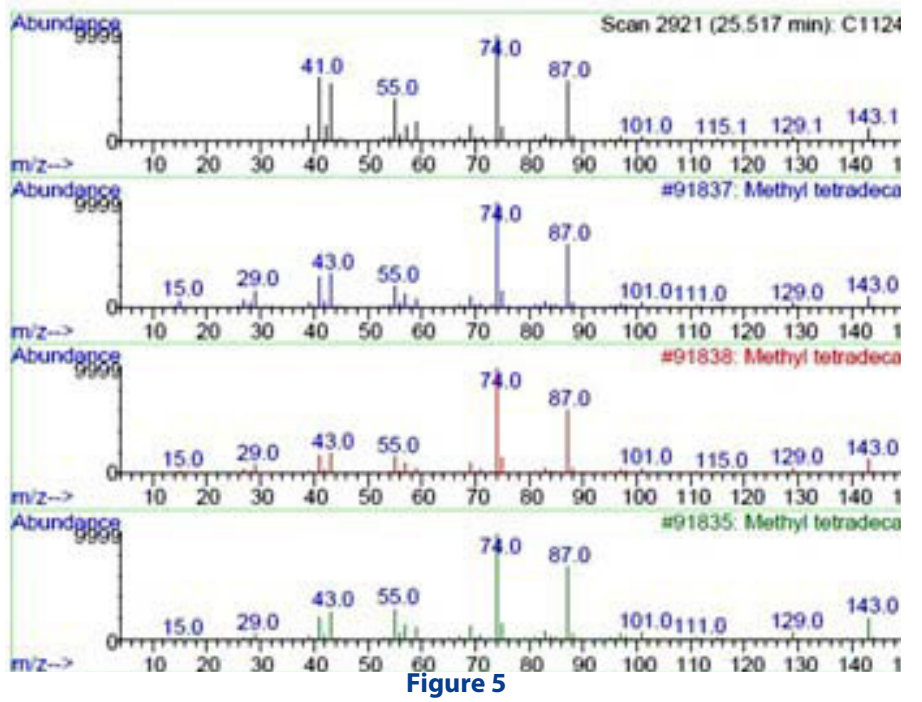

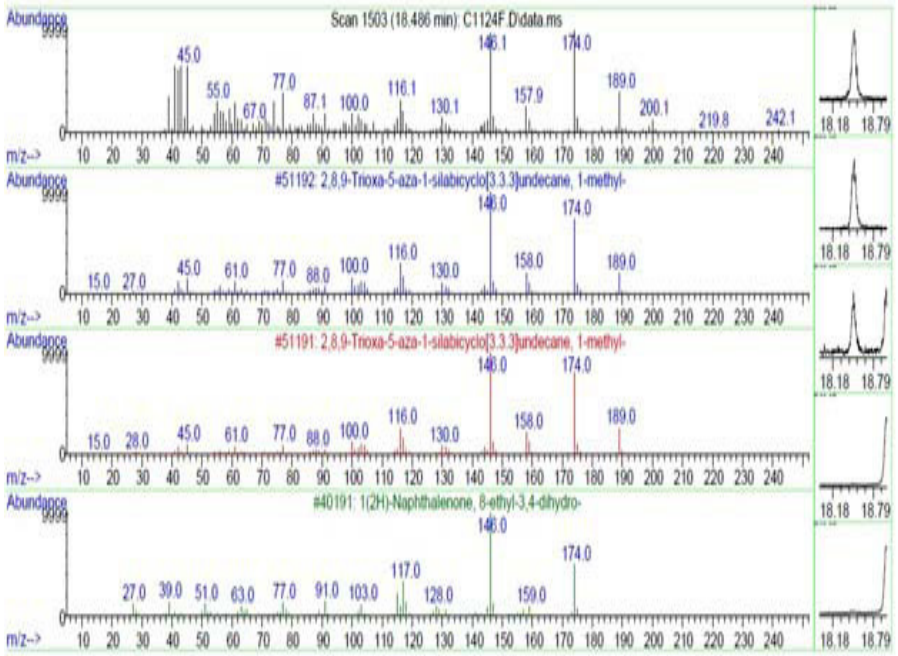

Figure 2

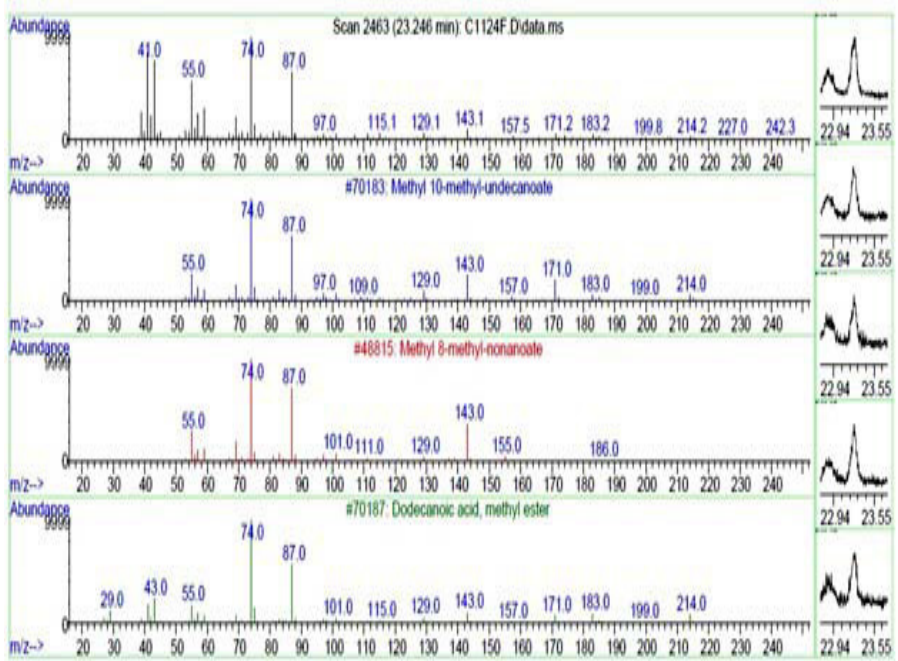

Figure 4

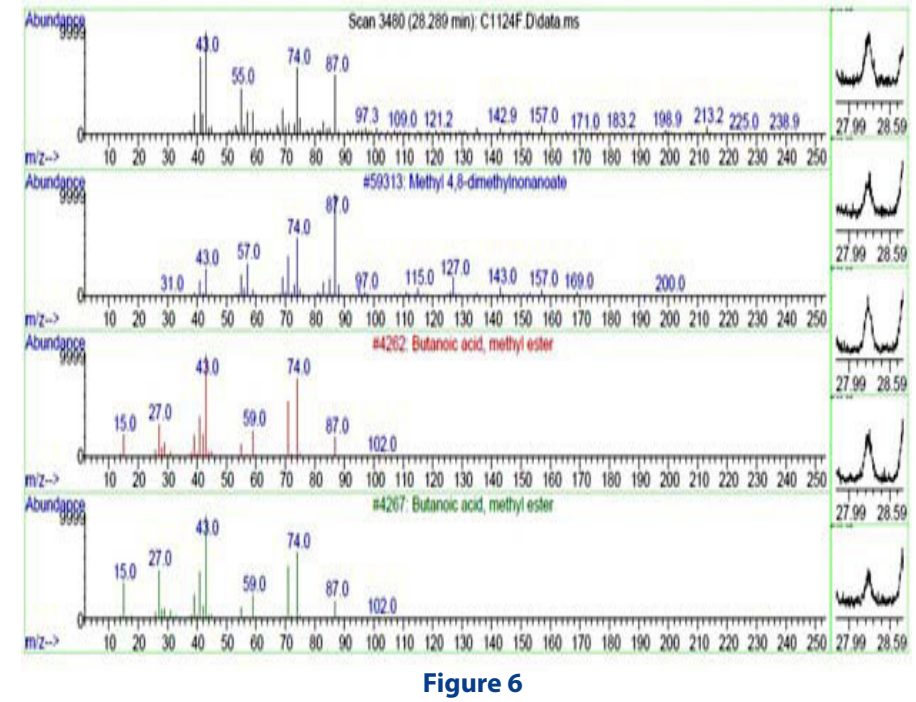

Figure 6 


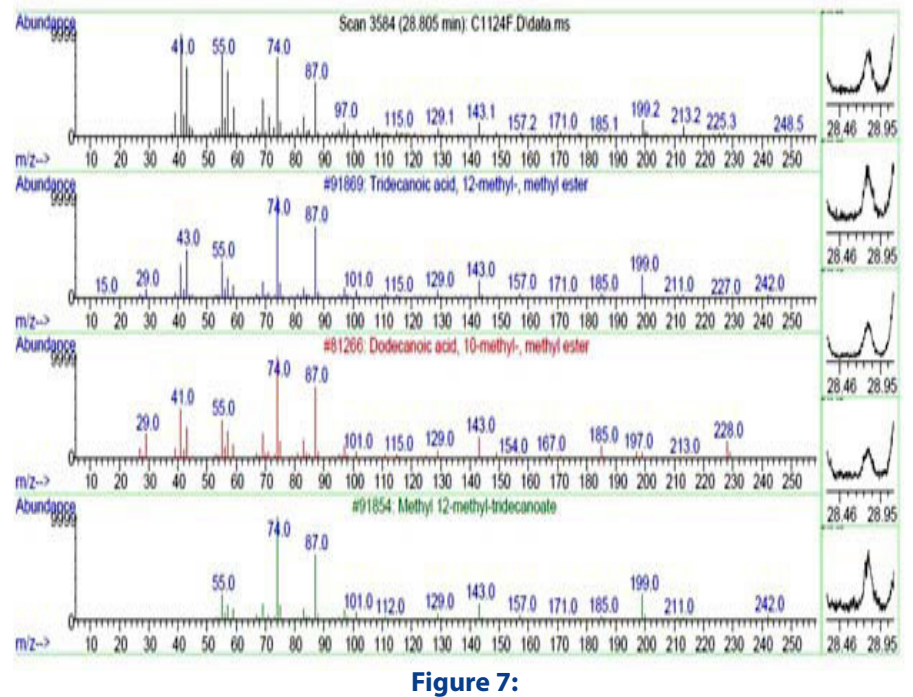

Figure 1-7: GC-MS Spectrum of Indrakeeladri

\section{Table 1: Compounds analyzed by GC-MS in INDRAKEELADRI drug sample used for stroke}

\begin{tabular}{|c|c|c|c|c|c|c|c|}
\hline S. No. & RT & Name of the compound & MW & MF & Area (\%) & CAS\# & Reference \\
\hline 1 & 18.486 & $\begin{array}{l}\text { 2,8,9-Trioxa-5-aza-1-silabicyclo[3.3.3] undecane, } \\
\text { 1-methyl- }\end{array}$ & 189.3 & C $7 \mathrm{H} 15 \mathrm{NO} 3 \mathrm{Si}$ & 1.82 & 002288-13-3 & 20 \\
\hline 3 & 18.982 & Dodecanoic acid, methyl ester & 214.3 & C $13 \mathrm{H} 26 \mathrm{O} 2$ & 17.14 & $000111-82-0$ & 23 \\
\hline 4 & 18.982 & Undecanoic acid, 10-methyl-, methyl ester & 214.3 & C $13 \mathrm{H} 26 \mathrm{O} 2$ & 17.14 & $5129-56-6$ & 24 \\
\hline 7 & 23.246 & Dodecanoic acid, methyl ester & 214.3 & $\mathrm{C} 13 \mathrm{H} 26 \mathrm{O} 2$ & 1.99 & $000111-82-0$ & 23 \\
\hline 8 & 25.517 & Methyl tetradecanoate & 242.4 & $\mathrm{C} 15 \mathrm{H} 30 \mathrm{O} 2$ & 76.12 & 000124-10-7 & 26 \\
\hline 9 & 28.289 & Methyl 4,8-dimethylnonanoate & 200.3 & $\mathrm{C} 12 \mathrm{H} 24 \mathrm{O} 2$ & 1.08 & 013758-80-0 & 27 \\
\hline 10 & 28.289 & Butanoic acid, methyl ester & 102.1 & $\mathrm{C} 5 \mathrm{H} 10 \mathrm{O} 2$ & 1.08 & $000623-42-7$ & 28 \\
\hline
\end{tabular}

RT: Retention time; MW: Molecular weight; MF: Molecular formula, CAS: Chemical Abstract Service

\section{CONCLUSION}

Indrakeeladri drug sample for treatment of stroke revealed the presence of methyl tetradecanoate, dodecanoic acid methyl ester and methyl 10-methyl undecanoate as the major constituents. Their role in treatment of stroke has to be studied further.

\section{ACKNOWLEDGEMENTS}

We thank our patients who voluntarily provided the drug sample for analysis.

\section{FUNDINGS}

The authors declare that they have received no funding for the research reported.

\section{COMPETING INTERESTS}

We declare that we have no competing interests.

\section{AUTHORS' CONTRIBUTIONS}

Drafting of themanuscript: Sridhar, Ram Dhishana, Ramaiah. Critical revision of themanuscript for importantintellectual content: Sundarachary, Sridhar, Ram Dhishana, Ramaiah, Lalitha.Technical,or material support: Sridhar, Ram Dhishana, Lalitha, Ramaiah,. Study supervision: Sundarachary.

\section{REFERENCES}

1. Wells BG, DiPiro TP, Schwinghammer LT, DiPiro VC. Pharmacotherapy: A Pathophysiologic Approach, seventh edition, Published by McGraw-Hill Companies, Inc., New York. 2008;1643(26-9):156-62.

2. Smith SW, English JD, Johnston SC, Fauci AS, M.D, Kasper LD, M.D, Longo DL, M.D. et. al., Cerebrovascular diseases. Harrison's Principles of Internal Medicine. $172 ; 513$

3. Smith SW, Hauser LS, Donald J. Easten. Cerebrovascular accident, Harrison's Principle of Internal Medicine, 3270-99

4. Aggarwal A, Aggarwal P, Khatak M, Khatak S. Cerebral Ischemic Stroke: Sequels Of Cascade. International Journal of Pharma and Bio Sciences, 2010;1(3):1-24.

5. Fanari Z, Malodiya A, Weiss SA, Hammami S, Kolm P, Weintraub WS. Long-term use of dual antiplatelet therapy for the secondary prevention of atherothrombotic events: Meta-analysis of randomized controlled trials. Cardiovascular Revascularization Medicine. 2016 Jul 20

6. Wassef A, Butcher K. Novel oral anticoagulant management issues for the 
stroke clinician. International Journal of Stroke. 2016 Jul 27:1747493016660100.

7. Nasiri J, Ariyana A, Yaghini O, Ghazavi MR, Keikhah M, Salari M. Neurological outcome after arterial ischemic stroke in children. Advanced Biomedical Research. 2016;5.

8. Kumar $\mathrm{A}$, Kumar $\mathrm{SH}$, Kaur $\mathrm{A}$. Role of herbal drugs in treatment and prevention of stroke..

9. Pandian JD, Liu M, Misbach J Venketasubramanian N. Alternative therapies for stroke treatment in Asia. International Journal of Stroke. 2011;1;6(6):541-3.

10. Feigenson JS, McDowell FH, Meese PH, McCarthy ML, Greenberg SD. Factors influencing outcome and length of stay in a stroke rehabilitation unit. Part 1. Analysis of 248 unscreened patients--medical and functional prognostic indicators. Stroke. 1977;1;8(6):651-6.

11. Davalos A, Cendra E, Teruel J, Martinez M, Genis D. Deteriorating ischemic stroke Risk factors and prognosis. Neurology. 1990;1;40(12):1865.

12. Pandian JD, Jaison A, Deepak SS et al. Public awareness of warning symptoms, risk factors, and treatment of stroke in northwest India. Stroke 2005;36(6):644 8. http://dx.doi.org/10.1161/01.STR.0000154876.08468.a0 ; PMid:15662041.

13. Lowery, TH, Richardson, KS., Mechanism and Theory in Organic Chemistry, Harper Collins Publishers 3rd ed. 1987 ISBN 0-06-364044-9.

14. Crowley. et al., Journal of Paint Technology 1966;38:496

15. Maštovská k, Lehotay SJ. Evaluation of common organic solvents for gas chromatographic analysis and stability of multiclass pesticide residues. Journal of Chromatography A 25;1040(2):259-72.

16. Adlard ER, Handley, Alan J. (2001). Gas chromatographic techniques and applications. London: Sheffield Academic. ISBN 0-8493-0521-7.

17. Weber, Armin; Maurer, Hans W.; Pfleger, Karl (2007). Mass Spectral and GC Data of Drugs, Poisons, Pesticides, Pollutants and Their Metabolites. Weinheim: Wiley-VCH. ISBN 3-527-31538-1.

18. Niessen WMA. (2001). Current practice of gas chromatography-mass spectrometry. New York, N.Y: Marcel Dekker. ISBN 0-8247-0473-8. http://dx.doi. org/10.1201/9781420029512.

19. Mc Ewen, Charles N, Kitson, Fulton G, Larsen. Barbara Seliger (1996). Gas chromatography and mass spectrometry: a practical guide. Boston: Academic Press. ISBN 0-12-483385-3.

20. Banel A, Zygmunt B. Application of gas chromatography-mass spectrometry preceded by solvent extraction to determine volatile fatty acids in wastewater of municipal, animal farm and landfill origin. Water Sci Technol. 2011;63(4):590-7. http://dx.doi.org/10.2166/wst.2011.204; PMid:21330701.

21. National Center for Biotechnology Information. PubChem Compound Database; $C I D=16797$.

22. National Center for Biotechnology Information. PubChem Compound Database; $C I D=589818$.

23. John W. Blunt, Murray H. G. Munro. Dictionary of Marine Natural Products, P. No 2179, published by Chapman and Hall/CRC; 1 Har/Cdr edition, 2007. ISBN10: 0849382165.

24. National Center for Biotechnology Information. PubChem Bioassay Database; $\mathrm{AID}=651838$.

25. National Center for Biotechnology Information. PubChem Compound Database; $C I D=554144$.

26. National Centre for Biotechnology Information. PubChem Compound Database; $C I D=206119411$.
27. National Center for Biotechnology Information. PubChem Compound Database; $\mathrm{CID}=31284$

28. National Center for Biotechnology Information. PubChem Compound Database; $C I D=560158$.

29. National Center for Biotechnology Information. PubChem Compound Database; $\mathrm{CID}=12180$.

30. National Center for Biotechnology Information. PubChem Compound Database; $\mathrm{CID}=21204$

31. National Center for Biotechnology Information. PubChem Compound Database; $C I D=521323$.

32. Rathore SS, Hinn AR, Cooper LS, Tyroler HA, Rosamond WD. Characterization of incident stroke signs and symptoms findings from the atherosclerosis risk in communities study. Stroke. 2002;1;33(11):2718-21.

33. Adams HP, del Zoppo G, Alberts MJ, Bhatt DL, Brass L, Furlan A, et al. Guidelines for the Early Management of Adults With Ischemic Stroke A Guideline From the American Heart Association/American Stroke Association Stroke Council, Clinical Cardiology Council, Cardiovascular Radiology and Intervention Council, and the Atherosclerotic Peripheral Vascular Disease and Quality of Care Outcomes in Research Interdisciplinary Working Groups: The American Academy of Neurology affirms the value of this guideline as an educational tool for neurologists. Circulation. 2007;22;115(20):e478-534.

34. Omura S, Nakagawa A, Fukamachi N, Otoguro K, Kobayashi B. Aggreceride, a new platelet aggregation inhibitor from Streptomyces. The Journal of Antibiotics. 1986;39(8):1180-1. http://dx.doi.org/10.7164/antibiotics.39.1180; PMid:3759668.

35. Sato J, Yamamoto Y, Nakamura T, Ishida S, Takagi Y. Toxicity studies of tetradecanoic acid, 2-sulfo-, 1-methylester, sodium salt (C14-MES). J Toxicol Sci. 2005;30(4):339-47. http://dx.doi.org/10.2131/jts.30.339 ; PMid:16404142.

36. Narasimhan B, Mourya $V$, Dhake A. Design, synthesis, antibacterial, and QSAR studies of myristic acid derivatives. Bioorg Med Chem Lett. 2006;1;16(11):30239.

37. Lomarat P, Chancharunee S, Anantachoke N, KitphatiW, Sripha K, Bunyapraphatsara N. Bioactivity-guided Separation of the Active Compounds in Acacia pennata Responsible for the Prevention of Alzheimer's Disease. Natural product communications. 2015;10(8):1431-4.

38. Lucie AT, Dogo S, Béranger LD, Florent BO, Talla GM, Anna T, et al. Chemical characterization and insecticidal activity of ethyl acetate and dichloromethane extracts of Drypetesgossweileri against Sitophilus zeamais, Triboliumcastaneum and Rhyzoperthadominica. Journal of Life Sciences. 2013;1;7(10):1030.

39. Yang, D; Pornpattananangkul, D; Nakatsuji, T; Chan, M; Carson, D; Huang, CM; Zhang, L (2009). "The Antimicrobial Activity of Liposomal Lauric Acids Against Propionibacterium acnes". Bio materials. 30(30):6035-40. http://dx.doi. org/10.1016/j.biomaterials.2009.07.033 ; PMid:19665786 PMCid:PMC2735618

40. Mensink RP, Zock PL, Kester ADM, Katan MB (May 2003). "Effects of dietary fatty acids and carbohydrates on the ratio of serum total to HDL cholesterol and on serum lipids and apolipoproteins: a meta-analysis of 60 controlled trials". American Journal of Clinical Nutrition, 77(5):1146-55. ISSN 0002-9165.

41. Puri JK, Singh R, Chahal VK. Silatranes: a review on their synthesis, structure, reactivity and applications. Chemical Society Reviews. 2011;40(3):1791-840. http://dx.doi.org/10.1039/B925899J; PMid:21170448.

42. Duke JA. Handbook of biologically active phytochemicals and their activities. CRC Press, Inc.; 1992.

Cite this Article: Nagarjunakonda S, Amalakanti S, Dhishana SR, Ramaiah M, Rajanala L. GC-MS Analysis of Indrakeeladri native medicine used in the treatment of stroke. Pharmacogn J. 2017;9(1):102-6. 